\title{
Integrated modeling of river- corridor connectivity, reactivity and outcomes for receiving waters
}

\author{
JUDSON HARVEY ${ }^{1}$
}

${ }^{1}$ U.S. Geological Survey, Reston, VA

Rivers are not pipes - they are biologically-reactive corridors with permeable and reactive interfaces that store water, sediments, carbon and nutrients; filter and transform contaminants; and provide metabolic processing and habitats that support valued ecological services for society. Only recently has the historically discipline-specific concepts from watershed and aquatic ecology come to be combined in scalable and transferable models for river corridors that can be tailored to meet societal needs. We highlight an integrated metric for river corridor functions, hydrologic connectivity, which previously lacked clarity and a quantitative definition, but recently has evolved towards widely applicable quantitative measures based on commonly available data. Hydrologic connectivity quantifies the degree of connection between the river's main channel with the hydrologically, biologically, and geochemically active sub-environments that surround the main channel. A typical purpose of hydrologic connectivity measures is to assess dominant controls and outcomes for water quality and ecology as they vary with basin size, hydroclimate, land-use and land-cover and implementation of specific management practices. Physical and biological interactions in river corridors that control water quality are clarified by quantifying the degree of river connectivity with floodplains, subsurface hyporheic zones, and ponds and reservoirs, including the degree of biological activity and biogeochemical reactivity in those subenvironments, relative to downstream transport. Patterns of hydrologic connectivity can reveal, for example, how past river management strategies and engineering solutions have caused unintended consequences for water quality. We advocate for modeling of hydrologic connectivity and reactivity in river corridors to better understand cumulative outcomes for water quality and ecological health, including global challenges such as the increasing occurrence and persistence of hypoxia and harmful aquatic blooms in receiving waters. 